\title{
Federal governance and the undying parade for universal health coverage in Nepal
}

\author{
Pratik Khanal ${ }^{1,3^{*}}$, Shiva Raj Mishra ${ }^{2,3}$ \\ ${ }^{1}$ Global Health Unit, Institute of Medicine, Kathmandu, Nepal \\ ${ }^{2}$ Nepal Development Society (NEDS), Bharatpur, Nepal \\ ${ }^{3}$ Health Prospect: Journal of Public Health
}

Received:

1 July 2018

Revised:

11 November 2018

Accepted:

22 November 2018

\section{*Corresponding author pratikkhanal@iom.edu. np}

\section{Background}

The governance in Nepal underwent a significant change after the promulgation of the Constitution of Nepal in September 2015. The country is administratively divided into 753 local government units, seven provincial governments and a central government [1]. The federal governance redistributed the decision making power and resources among the central, provincial and local governments in all sectors including health. In juxtaposition to the political scenario, health system in Nepal will be functioning under a new governance with Ministry of Health and Population (MoHP) at the central level, Ministry of Social Development at the provincial level and health section or health department under the local level governments. In this paper, we discuss about possible opportunities and challenges that Nepal could face in its journey to universal health coverage in the federal governance.

\section{Opportunities in federal governance \\ Translating policy into practice}

The health system of Nepal is currently guided by Constitution of Nepal 2015 [2], National Health Policy 2014 [3] and Nepal Health Sector Strategy (2015-2020) [4]. These three policies in turn are guided by the principles of human right, access, quality, health sector reform and multi-sectoral approach [4]. The federal governance will provide an opportunity for transforming these policies into practice, as well as provide more authority to sub-national governments in sharing and control of resources. However, subnational governments need to prioritize investing in their key health priorities as well as closely align with the central governments for implementing national health policies and programs. For example, addressing undernutrition could be a priority for Province 2 (29\% female and 23\% male are too thin for their height), where as addressing overweight/obesity can be a priority for province 3(35\% female and 24\% male are either overweight or obese) [5].The Demographic and Health Survey 2016 [5] has highlighted geographical disparities in health indicators as well as displayed a need for local and provincial government to narrow these disparities immediately.

\section{Local governments take charge for health}

Presence of local government officials after more than 15 years has raised hope for strengthening health system in Nepal. Local governments are expected to engage in health planning and management, and assuming responsibility for health of the population by ensuring provision of quality services and allocation of resources to the health sector. Local level governments will be responsible for ensuring basic health services, monitoring social health protection measures including health insurance and addressing equity issues by focusing on underserved populations which will be detrimental to achieve universal health coverage. A functional health system managed by local level governments will thus be a sustainable measure to ensure the spirit of federal governance.

\section{Health as development agenda}

Ministry of Social Development at the province level has been assigned to oversee sectors such as health, education, women and child welfare, labor, culture and social protection. This will be an opportunity to drive health as a development agenda, as well as materialize the principle of health beyond health. Further, multi-sectoral planning would minimize resource duplication and integrate health across different sectors. The same applies to planning at local level where health could fit as a social agenda with local level governments taking ownership to address the health priorities which were formerly owned and addressed centrally.

\section{Strengthening primary health care}

Government of Nepal has envisioned for establishing municipal hospital in each local level government 
and health unit at ward level. However, building health infrastructure alone will not be enough to bring services closer to the population as health is affected by complexities both inside and outside of health sector. Human resources with appropriate skill mix, use of appropriate technology and information system, strong leadership and governance and community participation need to be well in place to deliver quality and community trusted services and promote healthy lifestyles. Importantly, it is necessary to take into account the broader social determinants of health while planning for health interventions. The key to building health systems in Nepal would be strengthening primary health care for which the role of local level governments would be important.

\section{Challenges in federal governance \\ Inheritance of structural inequities}

New federal governance inherits some structural challenges from highly centralized governance in the past which have led to multitude of inequalities in health indicators across different socio-economic groups and geographical regions. Poverty level varies across provinces with Karnali province and province 2, being poorest in socio-economic indicators [6]. Availability of resources including the distribution of health facilities and human resources is not equitable at the provincial level. For instance, 11 central hospitals under Ministry of Health and Population are in Kathmandu valley (Province 3) [7] while the distribution of private hospitals and medical colleges depicts similar scenario with most of them centered in Kathmandu and urban areas [8]. Health facilities in the rural areas are however under-resourced and crippled with geographical hindrances and poor retention of health workers [9]. Federal governance would require management of existing human resource for health at national and sub-national levels. The current human resource problems related to availability and distribution might pose difficulty for effective functioning of health system.

\section{Health as a conflicting priority}

Health might be a conflicting priority at the local level government with the local body officials showing more interest in infrastructure development like roads, electricity and water supply. Though the infrastructure development helps to set the foundation of the public health, curtailing health sector resources to other sectors will jeopardize the decades of achievement in health sector. Similar experience from Kenya [10] suggest that local governments were influenced by power and politics with community based health interventions given low priority after devolution.

\section{Health financing}

The proportion of annual health sector budget has been decreasing in Nepal [9] which affects the health service delivery system at all levels. In the changed federal context, financing health system at national and sub-national levels will be a challenge for the country in the absence of a robust health financing strategy. Sub-national governments, in addition to receiving budget from the central government, can generate revenue by expanding tax structure on tobacco, alcohol, and sugar-sweetened beverages. In the absence of specific guidelines, local governments cannot practice these tax structures as well monitor tax eviction that might affect revenue generation.

Introduction of health insurance program was a welcome move in the country for pooling risks but remained insufficient thus far to achieve universal health coverage as health system suffers from systemic challenges mainly inequitable distribution of health resources and compromised quality of health services [11-13].

\section{Performance of health system and quality}

According to The Lancet Global Health Commission [14], deficit in quality health care contribute to $60 \%$ of total deaths related to health care while the remaining is related to non-utilization of health services. The commission has further stressed on redesigning service delivery where maximization of health outcomes is focused over geographical access to health services. Sadly, in Nepal, health system challenges and discussions are dominated by access related problems while quality component of health care has been overlooked. With local governments taking the gear of health system, initiatives to improve health system performance need to focus on quality improvement strategies, as well as improving local level planning, implementation and evaluation of health programs.

\section{Way Forward}

Though federal governance will add administrative burden, it is expected to contribute to the national development in long run as well as facilitate planning and effective utilization of resources. The spirit of universal health coverage envisioned in Alma Ata Declaration are directly linked to the provision of quality health services that are readily accessible, affordable and equitable in distribution across all geographic regions, and comes along a strong mechanism of risk pooling that exists at all levels of health system. This however requires greater engagement of local level governments in health matters.

To harness the outputs of real decentralization through federal governance, province and local governments need to be in charge and in tandem with the central government. We put forward the following discussions which may supports our earlier arguments on institutionalizing health system in the federal context and in achieving universal health coverage:

I. Inadequate capacity among province and local level governments in health sector planning can be improved by empowering local decision makers to invest in health, engaging them in making healthy public policies and promoting accountability towards health in addition to devolution of authority and resources. Greater capacity for management of drugs and supplies, and outbreak management 
will also be required at these levels. Effective coordination and communication channels need to be there between different levels of governments for ensuring the provision of basic health services, increasing population coverage in health insurance and other social security measures, and in providing quality and equitable health services.

II. Strengthening health system at local level government will be a crucial investment opportunity for the government bringing health services closer to the population. The focus should be on developing healthy public policies, quality health service delivery with minimum standards of care, management of human resource for health and promoting healthy behaviors across populations. There need to be a strong linkage between health institutions at all levels with sound information system and referral system. Further, a massive decentralization is also necessary for non-governmental organizations in Nepal which need to move in the spirit of federalism to ensure distributive justice.

III. There is a dire need of assessment of health resources and health indicators at province and local level, identification of underserved populations or regions and, generation and uptake of evidence while designing any health interventions. Local government officials need to be encouraged to invest in best possible interventions taking into account the local burden of disease and community needs.

IV. Role sharing between different levels of government should be clearly identified with proper distribution of power and financial autonomy. While there should be check and balance from the center, this should however not derail the functioning of health system of province and local level.

\section{References}

1. Central Bureau of Statistics. National Population and Housing Census 2011 Household and Population by Sex (Based on new structure of 753 local unit). In: CBS, editor. Kathmandu: CBS; 2017.

2. Government of Nepal. Constitution of Nepal 2015. Kathmandu: Constituent Assembly Secretariat. 2015.

3. Ministry of Health. National Health Policy 2014. Kathmandu: Government of Nepal; 2014.

4. Ministry of Health and Population. Nepal Health Sector Strategy (2015-2020). Kathmandu: Government of Nepal; 2015.

5. MOH/Nepal NEN, and ICF. Nepal Demographic and Health Survey 2016. Kathmandu, Nepal: Ministry of Health, Nepal, 2017.

6. National Planning Commission GoN, University of Oxford. Nepal's Multidimensional Poverty Index: Analysis Towards Action. Kathmandu, Nepal: National Planning Commission 2017.

7. Ministry of Health and Population. Central Hospitals Kathmandu2017 [cited 2018 6/11/2018]. Available from: http://www.mohp.gov.np/content/central-hospital.

8. Government of Nepal. A Report On Census of Private Hospitals in Nepal 2013. In: Statistics CBo, editor. Kathmandu: CBS; 2014.

9. Khanal P. Right to Health in Nepal: Commitment versus Challenges. Health for All. 2015;2(1):3-5.

10. McCollum R, Theobald S, Otiso L, Martineau T, Karuga R, Barasa E, et al. Priority setting for health in the context of devolution in Kenya: implications for health equity and community-based primary care. Health policy and planning. 2018.

11. Mishra SR, Khanal P, Karki DK, Kallestrup P, Enemark U. National health insurance policy in Nepal: challenges for implementation. Global health action. 2015;8(1):28763. 12. Pokharel R, Silwal PR. Social health insurance in Nepal: A health system departure toward the universal health coverage. The International journal of health planning and management. 2018.

13. Mishra SR, Khanal P, Dhimal M. Nepal's quest for Universal Health Coverage. Journal of Pharmacy Practice and Community Medicine. 2016;2(4).

14. Kruk ME, Gage AD, Arsenault C, Jordan K, Leslie HH, Roder-DeWan S, et al. High-quality health systems in the Sustainable Development Goals era: time for a revolution. The Lancet Global Health. 2018;6(11):e1196-e252. 